2 Tsiquaye KN, Portmann B, Tovey G, Kessler H, Hu S, Lu XZ, et al. Non-A non-B hepatitis in persistent carriers of hepatitis B virus. $f$ Med Virol 1983;11:179-89.

3 Hollinger FB, Dolana G, Thomas W, Gyorkey F. Reduction in risk of hepatitis transmission by heat-treatment of a human factor VIII concentrate. $\mathcal{F}$ Infect Dis 1984;150:250-62

4 Baginski I, Chemin I, Hantz O, Pichoud C, Jullien AM, Chevre JC et al. Transmission of serologically silent hepatitis B virus along with hepatitis C virus in two cases of post-transfusion hepatitis. Transfusion 1992;32:215-20.

5 Aach RD, Szmuness W, Mosley JW, Hollinger FB, Kahn RA, Stevens CE, et al. Serum alanine aminotransferase of donors in relation to the risk of non-A, non-B in recipients: the transfusion-transmitted viruses study. N Engl F Med 1981;304:989-94.

6 Stevens CE, Aach RD, Hollinger FB, Mosley JW, Szmuness W, Kahn RA et al. Hepatitis $\mathrm{B}$ virus antibody in blood donors and the occurrence of non-A, non-B hepatitis in transfusion recipients: the transfusion-transnon-A, non-B hepatitis in transfusion recipients:
mitted viruses study. Ann Intern Med 1984;101:733-8.

7 Aach RD, Stevens CE, Hollinger FB, Mosley JW, Peterson DA, Taylor PE et al. Hepatitis $\mathrm{C}$ virus infection in post-transfusion hepatitis. $N$ Engl $\mathcal{F} \mathrm{Med}$ et al. Hepatitis C

8 Mosley JW, Aach RD, Hollinger FB, Stevens CE, Barbosa LH, Nemo GJ et al. Non-A, non-B hepatitis and antibody to hepatitis $\mathrm{C}$ virus. ҰAMA 1990;263: $77-8$.
9 Mimms L, Vallari DS, DuCharme L, Holland P, Kuramoto IK, Zeldis J. Specificity of anti-HCV ELISA assessed by reactivity to three immunodominant HCV regions. Lancet 1990;336:1590-1.

10 Vallari DS, Jett BW, Alter HJ, Mimms LT, Holzman R, Shih JWK. Serological markers of posttransfusion hepatitis $\mathrm{C}$ virus infection. $\mathcal{f}$ Clin Microbiol 1992;30:552-6.

11 Bukh J, Purcell RH, Miller RH. Importance of primer selection for the detection of hepatitis $C$ virus RNA with the polymerase chain reaction assay. Proc Natl Acad Sci USA 1991;89:187-91.

12 Eble K, Clemens J, Krenc C, Rynning M, Stojak J, Stuckmann J, et al. Differential diagnosis of acute viral hepatitis using rapid, fully automated immunoassays. f Med Virol 1991;33:139-50.

13 Conover WJ. Practical nonparametric statistics. 2nd ed. New York: Wiley, 1980:224.

14 Tateda A, Kikuchi K, Numazaki Y, Shirachi R, Ishida N. Non-B hepatitis in Japanese recipients of blood transfusions: clinical and serologic studies after the introduction of laboratory screening of donor blood for hepatitis B the introduction of laboratory screening

15 Gilles PN, Feg G, Chisari FV. Tumor necrosis factor alpha negatively regulates hepatitis $\mathrm{B}$ virus gene expression in transgenic mice. $f$ Virol 1992;66:3955-60.

(Accepted 23 August 1993)

\title{
Social deprivation and premature mortality: regional comparison across England
}

\author{
Margaret Eames, Yoav Ben-Shlomo, M G Marmot
}

\section{Abstract}

Objective-To investigate the pattern and size of the relationship between social deprivation in electoral wards and premature mortality for each health region in England.

Design-Ecological study using 1981 census variables and data on mortality for 1981-5.

Setting-14 regional health authorities in England.

Main outcome measure-Mortality under the age of 65 years from all causes, coronary heart disease, and smoking related diseases in men and women.

Results-Increasing deprivation was significantly associated with mortality from all causes, coronary heart disease, and smoking related diseases. The relationship was linear with no apparent threshold. Correlation coefficients were generally greater for deaths from all causes and smoking related diseases and for men compared with women. The slope of the relationship between deprivation and mortality varied among regions. Variations in mortality still existed between regions for equal levels of deprivation.

Conclusion-Deprivation of an area and premature mortality are strongly linked. The effects of deprivation can be seen throughout the range of affluence and are not limited to the poorest areas. Current targets for reducing coronary heart disease mortality may be achievable if the mortality in poor areas can be reduced to the rates in affluent areas.

\section{Department of}

Epidemiology and Public

Health, University College

London Medical School,

London WC1E 6EA

Margaret Eames, research

fellow in epidemiology

Yoav Ben-Shlomo, Wellcome research fellow

M G Marmot, professor

Correspondence to:

$M$ Eames, Senior Lecturer in

Medical Statistics, University

of Hertfordshire, Hatfield

AL10 9AB.

$B M 71993 ; 307: 1097-102$

\section{Introduction}

The Health of the Nation set targets for reducing mortality from coronary heart disease and advocated changes in lifestyle, particularly in smoking and diet, to meet them. ' This strategy is potentially an important step forward for public health in England. Changes in lifestyle, however, are likely to be effected to differing degrees in different subgroups of the population. The evidence suggests that this variation may have previously resulted in increased social differences in mortality from coronary heart disease and other diseases. ${ }^{2}$ If improvement in disease rates occurs only among the more wealthy sections of the community the health targets will be harder to achieve for the whole population and progress towards the World Health Organisation's goal of equity in health will be retarded.

Action to achieve health targets should therefore take into account social variations in disease for two reasons. Such variations may allow effective targeting of groups at higher risk, and an understanding of their causes may suggest ways of preventing them. One way to understand the causes is to examine the extent to which variations in mortality in small areas are related to socioeconomic factors. Socioeconomic status is a powerful predictor of mortality in individual people. ${ }^{3-5}$ Social variables related to social deprivation also predict geographical variations in mortality. ${ }^{6-8}$

Using data from 8464 electoral wards in England, we analysed the relationship for each ward between social deprivation and premature mortality (under 65) from all causes, coronary heart disease, and smoking related disease. Our aims were to measure $(a)$ the extent to which deprivation predicts mortality and $(b)$ the possible benefits of improving life circumstances.

\section{Methods}

We initially used three different measures of social deprivation: the Carstairs index, ${ }^{7}$ the Townsend index ${ }^{8}$ and the underprivileged area score. ${ }^{9}$ Table I shows the variables used in these indices. Data on socioeconomic variables for each ward were obtained from the 1981 census (SASPAC) ${ }^{9 a}$ and collated; the three social deprivation indices were calculated by using transformed summated normal scores of each component as published. ${ }^{7-9}$ Increasing scores indicate greater deprivation in all three indices.

Mortality statistics for England between 1981 and 1985 were obtained from the Office of Population Censuses and Surveys. Numbers of deaths from all causes, coronary heart disease, and smoking related

TABLE I-Socioeconomic components of each index

\begin{tabular}{lccc}
\hline Variable & Jarman & Carstairs & Townsend \\
\hline Unemployed & Yes & Yes & Yes \\
No car & No & Yes & Yes \\
Overcrowding & Yes & Yes & Yes \\
Social classes IV and V & No & Yes & No \\
Housing tenure & No & No & Yes \\
Unskilled & Yes & No & No \\
Lone pensioner & Yes & No & No \\
Children under 5 years old & Yes & No & No \\
Lone parent & Yes & No & No \\
Geographical mobility & Yes & No & No \\
Ethnic minority group & Yes & No & No \\
\hline
\end{tabular}

^Socioeconomic group 11 . 
diseases were obtained by age, sex, and electoral ward. Causes of death regarded as related to smoking are shown in table II. For each separate cause of death the numbers of deaths thought attributable to smoking were calculated from data in the 1982-8 cancer prevention study and the 1988 general household survey. ${ }^{10}$ The numbers of deaths overall that were attributable to smoking were then summed for each ward.

Deaths were assigned to electoral wards as defined at the time of death. Because some ward boundaries have changed since 1981 we reassigned deaths to wards as set in 1981. We obtained information on changes to electoral ward boundaries since 1981 from the frozen postcode directories of the Office of Population Censuses and Surveys. At the time of the 1981 census one ward, which has subsequently become part of North West Thames Regional Health Authority, was split between the North East Thames and North West Thames regions and has therefore been omitted from the analysis, leaving 8464 wards available for analysis.

Only the deaths of people under the age of 65 were considered for analysis of mortality from all causes and coronary heart disease. Only the deaths of people aged 35 to 64 were considered for analysis of mortality from smoking related diseases on the assumption that death under the age of 35 is unlikely to be attributable to smoking.

As populations with a larger proportion of older subjects will have higher death rates, variations in the population structure of different wards must be taken into account. Mortality in a ward was expressed as a standardised mortality ratio with the death rates for England and Wales as the standard rates. A value over 100 indicates more deaths and a value less than 100 fewer deaths than expected if the mortality in every ward was the same as that in England and Wales. Data on men and women were analysed separately. A $\chi^{2}$

TABLE II-Causes of death classified as related to smoking

\begin{tabular}{lc} 
& ICD code \\
\hline Cancer of: & \\
Lip, oral cavity, pharynx & $140-149$ \\
Oesophagus & 150 \\
Stomach & 151 \\
Liver & 155 \\
Pancreas & 157 \\
Larynx & 161 \\
Lung & 162 \\
Cervix & 180 \\
Bladder & 188 \\
Kidney & 189 \\
Unspecified site & 199 \\
Leukaemia & $204-208$ \\
Heart disease: & $410-414$ \\
Coronary artery & \\
Other & $430-438$ \\
Circulatory disease: & $440-448$ \\
Cerebrovascular & $490-492,496$ \\
Other & $401-405,415-417,420-429$ \\
Respiratory disease: & $531-533$ \\
Chronic obstructive lung & \\
Other & \\
Ulcer of stomach and duodenum & \\
\hline
\end{tabular}

ICD = International Classification of Diseases. heterogeneity test was used to examine regional differences in standardised mortality ratios.

Regional values of social deprivation were calculated from the mean of ward values. The relationship between social deprivation and mortality was investigated by the use of scatterplots, weighted correlation coefficients, and weighted linear regression for each region separately. The logarithmic value of the standardised mortality ratio was used because the simple ratio has a positively skewed distribution and because it allows the effects of several variables on mortality to be examined if a multiplicative model is assumed. ${ }^{11}$ Although the number of people resident in most wards is reasonable (median value 4330 residents), we used a weighting factor because standardised mortality ratios in some wards were based on few events. Use of a weighting factor diminishes the importance of ratios from small wards, which may distort the results because of random error. ${ }^{12}$ The observed and expected numbers of deaths were used as possible weighting factors, but all the results presented have used expected deaths as the weighting factor. To measure the possible effects of social deprivation on mortality a standardised regression effect was calculated for each region. This describes the percentage change in mortality associated with one standard deviation change in deprivation score. As this varies for each region, the value of the standard deviation for all of England was taken, thus enabling a comparison across regions. The regression coefficients for men and women in each region are shown in the appendix.

The methods assume that the relation between deprivation and mortality is linear. To avoid this assumption we also examined mortality in five equal groups of wards ranked by their deprivation score. The standardised mortality ratio for wards in each group was then plotted against the average social deprivation score for that group, allowing the relationship between social deprivation and mortality to be assessed for each region.

\section{Results}

Variations in deprivation and mortality were seen for men and women between regions (table III). The number of deaths varied by ward during 1981-5. For example, the median number of deaths from all causes in men under 65 was 31 (range 0-415) and that in women under 65 was $20(0-219)$. As expected, mortality ratios were greater in the north of England than in the south, and a $\chi^{2}$ test of heterogeneity between regions was highly significant for all three categories of mortality in men and women $(p<0.001)$. The degree and extent of deprivation, as shown by mean and standard deviation of the Townsend score, varied by region. For example, East Anglia, South Western, and Wessex regions had a narrow spread of scores and Merseyside, North East Thames, and Northern regions a wide spread.

TABLE III-Standardised mortality ratios and average deprivation scores for 14 regional health authorities in England

\begin{tabular}{|c|c|c|c|c|c|c|c|c|}
\hline \multirow[b]{2}{*}{ Region } & \multirow{2}{*}{$\begin{array}{l}\text { No of } \\
\text { wards }\end{array}$} & \multirow{2}{*}{$\begin{array}{l}\text { Townsend } \\
\text { score }\end{array}$} & \multicolumn{2}{|c|}{ All causes } & \multicolumn{2}{|c|}{ Coronary heart disease } & \multicolumn{2}{|c|}{ Smoking related diseases } \\
\hline & & & Men & Women & Men & Women & Men & Women \\
\hline South Western & 794 & $-1.05(2.22)$ & 91.5 & $89 \cdot 7$ & $91 \cdot 3$ & $79 \cdot 7$ & $83 \cdot 5$ & $78 \cdot 2$ \\
\hline Wessex & 597 & $-1.20(2.35)$ & $89 \cdot 1$ & $87 \cdot 9$ & $86 \cdot 2$ & $74 \cdot 1$ & $83 \cdot 2$ & $74 \cdot 9$ \\
\hline South West Thames & 493 & $-1.67(2.81)$ & 85.9 & $88 \cdot 6$ & $80 \cdot 2$ & $64 \cdot 9$ & $80 \cdot 2$ & $77 \cdot 9$ \\
\hline South East Thames & 652 & $.0 .17(3.56)$ & $95 \cdot 1$ & $94 \cdot 5$ & $87 \cdot 7$ & $80 \cdot 7$ & $90 \cdot 7$ & $89 \cdot 1$ \\
\hline North East Thames & 576 & $0.98(4 \cdot 28)$ & $96 \cdot 3$ & $97 \cdot 5$ & $90 \cdot 1$ & $84 \cdot 3$ & $94 \cdot 7$ & $94 \cdot 3$ \\
\hline North West Thames & 513 & $0.27(3.58)$ & $89 \cdot 5$ & 91.9 & $83 \cdot 4$ & $78 \cdot 4$ & $83 \cdot 9$ & $85 \cdot 4$ \\
\hline Oxford & 552 & $-1.35(2 \cdot 74)$ & $85 \cdot 0$ & $87 \cdot 0$ & $80 \cdot 8$ & $77 \cdot 3$ & $77 \cdot 7$ & $79 \cdot 2$ \\
\hline East Anglia & 573 & $-1 \cdot 11(2 \cdot 29)$ & $83 \cdot 4$ & $85 \cdot 1$ & $76 \cdot 5$ & $63 \cdot 9$ & $71 \cdot 2$ & $68 \cdot 8$ \\
\hline Midlands & 831 & $0.19(3.31)$ & $104 \cdot 0$ & 102.5 & $103 \cdot 4$ & $103 \cdot 9$ & $108 \cdot 3$ & $100 \cdot 7$ \\
\hline Trent & 832 & $-0.07(3.15)$ & 101.3 & 101.8 & 105.5 & $108 \cdot 7$ & $103 \cdot 2$ & $104 \cdot 5$ \\
\hline Merseyside & 312 & $0.93(4.49)$ & 113.3 & $114 \cdot 7$ & $118 \cdot 1$ & $130 \cdot 9$ & $123 \cdot 5$ & $133 \cdot 3$ \\
\hline North Western & 528 & $1.00(3.80)$ & $117 \cdot 0$ & 114.9 & $126 \cdot 0$ & $136 \cdot 1$ & $126 \cdot 8$ & $130 \cdot 9$ \\
\hline Yorkshire & 536 & $0.04(3.32)$ & 107.8 & $107 \cdot 2$ & $115 \cdot 4$ & $126 \cdot 1$ & $112 \cdot 7$ & $115 \cdot 8$ \\
\hline Northern & 675 & $2.06(3.97)$ & $116 \cdot 0$ & $115 \cdot 2$ & 121.0 & $143 \cdot 6$ & $125 \cdot 2$ & 135.5 \\
\hline
\end{tabular}


The weighted correlation coefficients linking deprivation to mortality, in general, produced similar values for all three deprivation scores. Overall, the Townsend score had slightly higher coefficients for more regions but the differences were small (further details available from us). In England overall the correlation coefficients for the Townsend, Carstairs, and under-

TABLE IV-Weighted correlation coefficients for Townsend deprivation score and different categories of mortality by region and sex

\begin{tabular}{|c|c|c|c|c|c|c|c|}
\hline \multirow[b]{2}{*}{ Region } & \multirow{2}{*}{$\begin{array}{l}\text { No of } \\
\text { wards }\end{array}$} & \multicolumn{2}{|c|}{ All causes } & \multicolumn{2}{|c|}{$\begin{array}{c}\text { Coronary heart } \\
\text { disease }\end{array}$} & \multicolumn{2}{|c|}{$\begin{array}{l}\text { Smoking related } \\
\text { diseases }\end{array}$} \\
\hline & & Men & Women & Men & Women & Men & Women \\
\hline South Western & 794 & 0.52 & 0.38 & $0 \cdot 35$ & 0.31 & 0.47 & 0.35 \\
\hline Wessex & 597 & 0.53 & 0.35 & 0.38 & $0 \cdot 28$ & 0.49 & 0.37 \\
\hline South West Thames & 493 & 0.57 & 0.46 & $0 \cdot 37$ & 0.31 & 0.56 & $0 \cdot 47$ \\
\hline South East Thames & 652 & 0.63 & $0 \cdot 49$ & $0 \cdot 35$ & 0.25 & 0.63 & $0 \cdot 49$ \\
\hline North East Thames & 576 & 0.73 & $0 \cdot 56$ & $0 \cdot 43$ & 0.37 & 0.65 & 0.46 \\
\hline North West Thames & 513 & 0.72 & 0.51 & $0 \cdot 40$ & $0 \cdot 26$ & 0.62 & 0.44 \\
\hline Oxford & 552 & 0.50 & 0.37 & 0.35 & $0 \cdot 29$ & $0 \cdot 47$ & $0 \cdot 40$ \\
\hline East Anglia & 573 & 0.30 & $0 \cdot 20$ & $0 \cdot 20$ & $0 \cdot 17$ & 0.34 & $0 \cdot 24$ \\
\hline Midlands & 831 & 0.69 & 0.57 & $0 \cdot 47$ & 0.47 & 0.67 & 0.60 \\
\hline Trent & 832 & 0.59 & 0.54 & 0.37 & 0.37 & 0.59 & 0.54 \\
\hline Merseyside & 312 & 0.76 & $0 \cdot 70$ & 0.56 & 0.55 & 0.76 & 0.71 \\
\hline North Western & 528 & 0.76 & 0.66 & 0.54 & 0.50 & 0.75 & 0.65 \\
\hline Yorkshire & 536 & 0.65 & $0 \cdot 60$ & $0 \cdot 46$ & $0 \cdot 40$ & 0.60 & $0 \cdot 60$ \\
\hline Northern & 675 & 0.63 & 0.50 & $0 \cdot 44$ & 0.39 & 0.62 & 0.55 \\
\hline All England & 8464 & 0.65 & 0.55 & $0 \cdot 45$ & 0.42 & 0.63 & 0.55 \\
\hline
\end{tabular}

TABLE $\mathrm{v}-$ Differences in mortality associated with one standard deviation of deprivation * for different categories of mortality by region and sex

\begin{tabular}{|c|c|c|c|c|c|c|c|}
\hline \multirow[b]{2}{*}{ Region } & \multirow{2}{*}{$\begin{array}{l}\text { No of } \\
\text { wards }\end{array}$} & \multicolumn{2}{|c|}{ All causes } & \multicolumn{2}{|c|}{$\begin{array}{l}\text { Coronary heart } \\
\text { disease }\end{array}$} & \multicolumn{2}{|c|}{$\begin{array}{c}\text { Smoking related } \\
\text { diseases }\end{array}$} \\
\hline & & Men & Women & Men & Women & Men & Women \\
\hline South Western & 794 & $20 \cdot 4$ & $17 \cdot 3$ & $20 \cdot 2$ & $22 \cdot 9$ & $31 \cdot 2$ & $24 \cdot 1$ \\
\hline Wessex & 597 & $19 \cdot 3$ & $14 \cdot 1$ & $21 \cdot 3$ & $22 \cdot 9$ & $31 \cdot 0$ & $24 \cdot 7$ \\
\hline South West Thames & 493 & $17 \cdot 6$ & $15 \cdot 8$ & $15 \cdot 6$ & $22 \cdot 6$ & 28.9 & $31 \cdot 3$ \\
\hline South East Thames & 652 & $18 \cdot 4$ & $13 \cdot 8$ & $12 \cdot 7$ & $14 \cdot 3$ & $24 \cdot 2$ & $22 \cdot 9$ \\
\hline North East Thames & 576 & $17 \cdot 1$ & $13 \cdot 5$ & $14 \cdot 0$ & $18 \cdot 2$ & $21 \cdot 7$ & $19 \cdot 4$ \\
\hline North West Thames & 513 & $19 \cdot 8$ & $13 \cdot 0$ & $13 \cdot 4$ & $15 \cdot 4$ & $24 \cdot 6$ & 21.5 \\
\hline Oxford & 552 & $19 \cdot 0$ & $14 \cdot 2$ & $18 \cdot 6$ & $20 \cdot 7$ & 25.9 & 23.8 \\
\hline East Anglia & 573 & $14 \cdot 3$ & $10 \cdot 1$ & $13 \cdot 3$ & $12 \cdot 7$ & $23 \cdot 7$ & $16 \cdot 8$ \\
\hline Midlands & 831 & $17 \cdot 4$ & $16 \cdot 3$ & $15 \cdot 9$ & $26 \cdot 3$ & 27.5 & 27.8 \\
\hline Trent & 832 & $14 \cdot 5$ & $16 \cdot 4$ & $12 \cdot 8$ & $20 \cdot 7$ & $24 \cdot 9$ & $27 \cdot 7$ \\
\hline Merseyside & 312 & $15 \cdot 1$ & $14 \cdot 6$ & $14 \cdot 6$ & $23 \cdot 3$ & $21 \cdot 7$ & $26 \cdot 8$ \\
\hline North Western & 528 & $18 \cdot 1$ & $16 \cdot 3$ & 14.9 & $25 \cdot 8$ & 25.5 & 27.8 \\
\hline Yorkshire & 536 & $15 \cdot 4$ & 15.5 & $16 \cdot 1$ & $19 \cdot 2$ & $23 \cdot 6$ & $26 \cdot 6$ \\
\hline Northern & 675 & $14 \cdot 8$ & $13 \cdot 6$ & $13 \cdot 1$ & $18 \cdot 2$ & $22 \cdot 1$ & $23 \cdot 1$ \\
\hline All England & 8464 & $18 \cdot 4$ & $16 \cdot 3$ & $17 \cdot 7$ & $25 \cdot 0$ & $27 \cdot 8$ & $28 \cdot 4$ \\
\hline
\end{tabular}

${ }^{\star}$ Standardised regression effect $(\%)$.
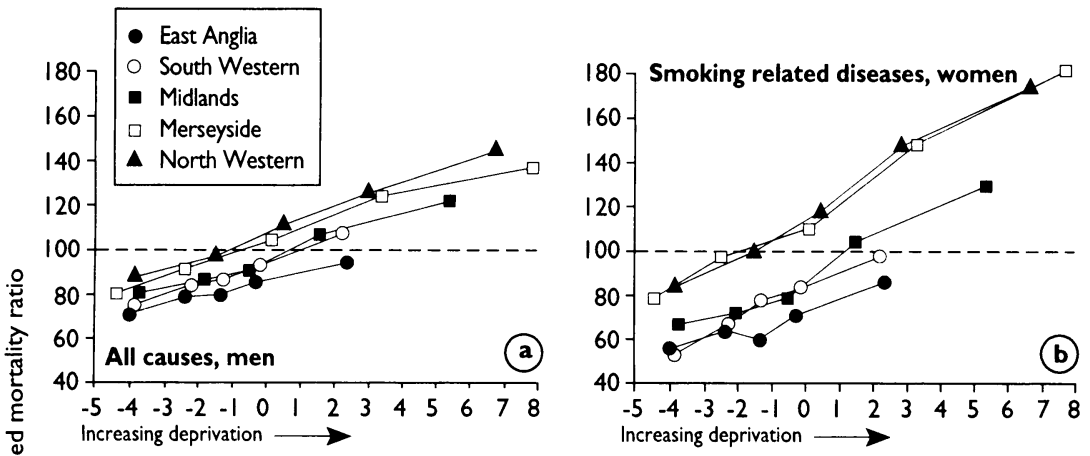

竞

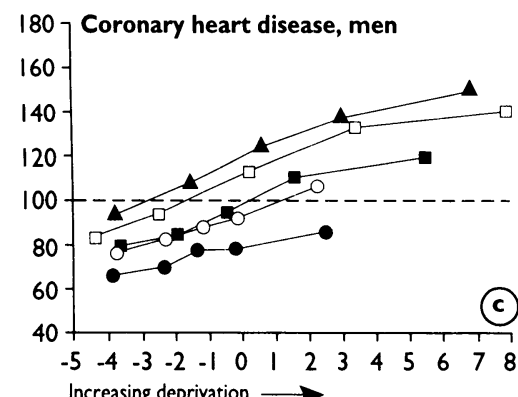

Townsend index

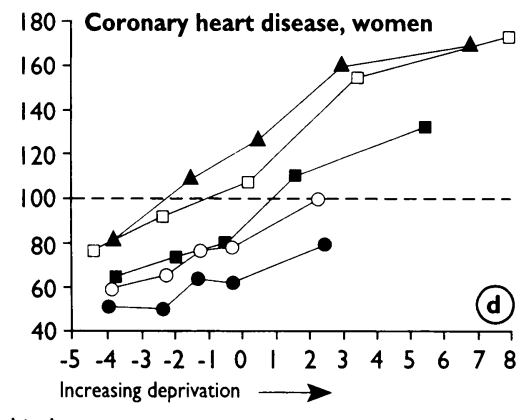

Relation between premature mortality from different causes in men and women and degree of deprivation divided into fifths for five representative regions priviledged area scores were $0.65,0.65$, and 0.60 for all causes in men; $0.55,0.55$, and 0.50 for all causes in women; $0.45,0.46$, and 0.39 for coronary heart disease in men; $0.42,0.43$, and 0.32 for coronary heart disease in women; $0.63,0.62$, and 0.56 for smoking related diseases in men; and $0.55,0.55$, and 0.46 for smoking related diseases in women. For clarity only the Townsend score is shown in all further results.

Table IV shows the weighted correlation coefficients for the Townsend score and deaths from all causes, coronary heart disease, and smoking related diseases. Coefficients were high for deaths from all causes and smoking related diseases and were smaller for coronary heart disease. In general, the coefficients were larger for men than women. Coefficients were generally greater for regions in the north of England compared with the south, but both north Thames regions had high coefficients.

The standard deviation for the Townsend score for the 14 regions combined was 3.44 and was used in calculating the standardised regression effects (table $\mathrm{V}$ ). For mortality from all causes the standardised regression effects for deprivation were almost all larger for men than women. This difference was generally reversed for mortality from coronary heart disease, although South Western and Wessex regions showed little sex difference. Regression effects associated with mortality from smoking related diseases show an inconsistent pattern. Regions in the south generally showed steeper gradients for men but in the north the effects were greater in women, particularly in Merseyside. A heterogeneity test for the gradients showed a significant interaction between deprivation and region $(p<0.01)$ for all three categories of mortality in men and women.

Increasing deprivation was associated with higher rates of premature death in every region. Mortality also increased systematically when wards, grouped in increasing fifths of deprivation, were compared. To show the different profiles of mortality we plotted five regions across England with varying standardised regression effects showing premature mortality from all causes in men, from smoking related diseases in women and from coronary heart disease in men and in women (figure; a-d). Each regional profile of mortality from all causes for women was similar to that of men, and the profile for smoking related diseases in men was similar to that of women, so these are not shown in the figure. Some regions showed a greater increase in premature mortality with deprivation, reflecting the differences in the standardised regression effects (table V). The greater effect of deprivation on mortality from coronary heart disease in women is seen by comparing parts $\mathrm{c}$ and $\mathrm{d}$ of the figure. In addition, at any given level of deprivation - for example, a Townsend score of zero-apparent regional differences in mortality remained. For example, throughout the range of deprivation the North Western region had higher standardised mortality ratios than the Midlands region, which in turn had higher ratios than East Anglia region. Even when two regions had a similar profile of deprivation-for example, South Western and East Anglia-this shift persisted.

In general, the regional patterns were parallel. In women, however, the patterns in South Western and East Anglia regions progressively diverged (figure; b). In affluent wards death rates were almost identical in the two regions, but the effect of increasing deprivation in South Western region seemed to be greater than it was in East Anglia. Death rates in less affluent wards in South Western region more closely matched those in the Midlands region than those in East Anglia.

Although not shown in the figure, the Thames regions also had wide ranges of deprivation. North East Thames in particular had a similar profile of 
deprivation to that of North Western region. At any given level of deprivation, however, mortality was lower in North East Thames than in the North Western region.

\section{Discussion}

Our results support the relationship between deprivation in an area and premature death. Studies in the Northern region and Scotland have shown strong correlations between measures of deprivation and mortality. ${ }^{78}$ Correlation coefficients of 0.64 and 0.78 were found between deprivation and standardised mortality ratios in men and women under 65 respectively. Differences in mortality between Scotland and England are also far better explained by the use of a deprivation measure than by the simple use of occupational social class. ${ }^{13}$

The causes of inequalities in health are not clear but both cultural or behavioural and materialist explanations have been suggested as important. ${ }^{14}$ Geographical variations in mortality probably do not reflect variations in provision of health care. ${ }^{16}$ Area deprivation scores may predict mortality by reflecting aggregate individual factors such as unemployment and low income. Classifying an area as deprived may mean simply that its inhabitants are of lower socioeconomic status. The scores may also act as a proxy measure of behavioural variables such as smoking. Areas with high mortality are more likely to have inhabitants who smoke more, eat more fat, and take less exercise than are areas with low mortality. ${ }^{17}$ Though area scores may act as correlates of individual behaviour, areas may also determine individual behaviour directly - through sociocultural mechanisms in determining attitudes and beliefs and structurally in limiting the opportunities for altering behaviour.

Alternatively, where a person lives may have a detrimental effect on health over and above the characteristics of the people who live there, as suggested by the Alameda county study. ${ }^{18}$ Though research has specifically examined the role of poor housing ${ }^{1920}$ and environmental factors, such as water hardness, ${ }^{21}$ little has been done on the possible effects of the area itself except in relation to the potential health hazards around toxic sites. ${ }^{22}$

DEPRIVATION AS A PREDICTOR OF PREMATURE DEATH

All the indices of social deprivation showed a remarkably similar degree of prediction within regions; for mortality from all causes and from smoking related diseases, they accounted for a fair proportion of the variation.

The association between area deprivation scores and mortality from coronary heart disease was weaker than for mortality from all causes and smoking related diseases. The expected and observed numbers of premature deaths from coronary heart disease in a ward were small. Therefore random variations in the number of deaths will have a disproportionate effect on the mortality ratio. This will reduce the apparent association between deprivation and mortality and may partly explain our findings. The same argument will apply when mortality in men and women is compared. For all three categories of mortality the number of women dying was much smaller than the number of men. For example, 1.7 times more premature deaths occurred in men than in women. The standardised regression effects for coronary heart disease were greater for women than for men in all regions except East Anglia. This suggests that deprivation may have a greater effect on coronary heart disease in women than men and is more pronounced in the north than the south. This is consistent with other research on sex differences in mortality and widening social inequalities based on social class. ${ }^{2}$ Possible clues to explain this observation come from sociological research. A qualitative study examining women with low incomes caring for preschool children suggested that the women's main way of coping with poverty was by sacrificing their own needs. ${ }^{23}$ Perhaps this results in a greater effect on a woman's risk of coronary heart disease.

REGIONAL VARIATIONS IN SMOKING RELATED MORTALITY

Regional variations in mortality from smoking showed an increase in mortality from the south to north of the country. Regional differences in the prevalence of smoking from the 1982 general household survey crudely support this pattern, the highest prevalence being in the Northern region (41\%) and the lowest in East Anglia (30\%), with little variation in the other regions. ${ }^{24}$ Of course, contemporary mortality should reflect earlier smoking behaviour, for which we have no reliable information. The results for mortality from smoking related diseases were similar to those for mortality from all causes. If deaths from smoking related diseases were a large proportion of all deaths the association between deprivation and mortality from all causes might reflect the association between deprivation and smoking rather than other effects of social deprivation. In fact, deaths related to smoking as calculated in this study, accounted for around $31 \%$ of all deaths in men and $21 \%$ of all deaths in women. Smoking is therefore unlikely to be the sole explanation of the link between deprivation and mortality, and other evidence suggests that the relationship between socioeconomic status and mortality is similar whether or not death is associated with smoking. ${ }^{3}$ The reason for the surprising sex differences in death from smoking related diseases in the north and south of England is not clear. They may reflect differences in smoking behaviour, confounding by other variables, or an interaction between smoking and area.

POSSIBLE EXPLANATIONS FOR REGIONAL VARIATIONS IN SLOPE

Regional variation in the degree to which deprivation predicted mortality and the strength of the relation could be explained in three ways. Firstly, variations in the correlation coefficients may be a statistical artefact as regions with a narrower range in deprivation also had lower coefficients-for example, East Anglia and South Western. This is a plausible suggestion as the narrower range of deprivation score for some regions would be expected to reduce the correlation coefficients. It does not, however, explain the differences in the effects of deprivation on mortality. South Western region, with a narrow range of deprivation, had one of the largest gradients, and Merseyside, with a wide range, had one of the smallest.

Secondly, the indices have a different social meaning in each region and thus measure deprivation to a differing degree. In some areas council flats may have been sold cheaply and housing tenure may be a less sensitive measure of wealth. Also, these indices correlate better in urban areas than in rural areas. ${ }^{8}$ Other variables, such as the presence of central heating or double glazing, may be more sensitive indicators of variations in socioeconomic conditions for these areas. This is analogous to the steeper gradient for mortality when individuals are classified not only by social class but also by car ownership and housing tenure. ${ }^{5}$

Finally, other factors have not been taken into account. In some areas deprivation may be a better marker for other factors affecting mortality. This may vary by region and thus alter the strength of the relation between deprivation and mortality.

We found that differences in mortality between 


\section{Public health implications}

- Geographical variations in rates of premature death are associated with social deprivation

- This study found that increasing deprivation was associated in all regions and at all levels with an increase in premature mortality from all causes, coronary heart disease, and smoking related diseases in men and women

- There was no upper or lower plateau to the relation between deprivation and mortality

- There is immense potential for reducing mortality if the number of premature deaths in poor areas fell to the numbers observed in affluent areas

regions were not explained entirely by their deprivation scores. Mortality from smoking related diseases in Eas Anglia was lower than that in the Midlands and South Western regions at any level of deprivation. $r$ To what degree these differences reflect the role of other factors unrelated to deprivation or the two other reasons given is not clear. The interaction between deprivation and region is interesting and deserves further investigation.

To summarise a ward by a single score simplifies what is a complex phenomenon. Even wards with similar scores differ in the values of the composite variables. Areas with similar deprivation scores but different death rates may differ in many other aspects, and detailed analyses of anomalous areas may illuminate interesting differences. ${ }^{25}$

We have examined only the relationship between deprivation and mortality. Associations between deprivation and measures of ill health have also been noted. ${ }^{726}$ Similar results are likely with measures such as years of potential life $\operatorname{los}^{27}$ and years free of disability. ${ }^{28}$

Our results for all three categories of mortality support other work showing the relative nature of deprivation. ${ }^{78}$ The relationship between deprivation and mortality was fairly continuous and was seen throughout the range of deprivation. Areas that in reality would not be labelled as deprived, still had higher mortality than the most affluent areas. Although, intuitively, increasing affluence may not be expected to have a continuous effect on mortality, this was not seen in this dataset. We therefore suggest that deprivation should be seen as comparative, with no specific threshold.

\section{IMPLICATIONS OF THE HEALTH OF THE NATION}

Proposed national targets for mortality from coronary heart disease make limited reference to geographical or social variations.' Social variations should not be ignored. Firstly, even if national targets for mortality from coronary heart disease and other diseases are met, current geographical or social differences may persist or increase. More favoured areas may be greater beneficiaries of health promotion than less favoured areas. The use of social deprivation scores has been suggested in modifying national to local targets. ${ }^{29}$ Secondly, one way of achieving national targets would be to reduce geographical and social variations. In other words, these targets could be achieved if the mortality of the least favoured areas could be reduced to the level of the more affluent. A shift in social deprivation for some regions may be associated with a reduction in mortality in line with or greater than current targets if areas currently rated in the worst third of the region could join those currently in the best third.

This research does not prove that the association between deprivation and mortality is causal, but it must be interpreted with the body of evidence on the effects of socioeconomic status on health. Geographical correlations between current deprivation and mortality have also been seen with earlier infant mortality. ${ }^{30} 31$ Relative deprivation may act throughout an individual's life course from the intrauterine environment to adulthood. The role of factors beyond the individual but relating to communities is harder to examine or measure. Some evidence exists to support the importance of social cohesion, family stability, and community solidarity in influencing mortality. ${ }^{32}$

How deprived areas should be targeted and what the most appropriate interventions are cannot be answered from our work. The traditional focus on individual risk factor modification has broadened to take on areas such as the social environment with, for example, the "Healthy Cities" project. ${ }^{33}$ Social directed policies such as improving child benefit and pensions and providing employment opportunities and good quality housing may also have a major impact. ${ }^{34}$ The potential for reducing mortality associated with deprivation is immense and remains a future challenge to all involved in public health.

We thank the Health Education Authority for funding ME as research fellow in epidemiology to work on this project. We also thank Madhavi Bajekal, department of general practice, St Mary's Hospital, London, for providing data on ward deaths and populations and census data, and Christine Callum, Health Education Authority, for the method in determining the smoking related deaths. Fiona Blythe was involved in the initial literature review. Professor B Jarman and the anonymous assessors provided useful comments. YB-S is funded by a Wellcome fellowship in clinical epidemiology.

\section{Appendix}

Table A shows the $\beta$ regression coefficients used in calculating standardised refression effects and based on the expected number of deaths. Regression coefficients based on the observed number of deaths were smaller but showed the same pattern.

TABIE A-Regression coeficients (SE) for several categories of mortality by region and sex

\begin{tabular}{|c|c|c|c|c|c|c|c|}
\hline \multirow[b]{2}{*}{ Region } & \multirow{2}{*}{$\begin{array}{l}\text { No of } \\
\text { wards }\end{array}$} & \multicolumn{2}{|c|}{ All causes } & \multicolumn{2}{|c|}{ Coronary heart disease } & \multicolumn{2}{|c|}{ Smoking related diseases } \\
\hline & & Men & Women & Men & Women & Men & Women \\
\hline South Western & 794 & $0.0539(0.0031)$ & $0.0463(0.0040)$ & $0.0534(0.0051)$ & $0.0599(0.0075)$ & $0.0790(0.0053)$ & $0.0627(0.0067)$ \\
\hline Wessex & 597 & $0.0514(0.0034)$ & $0.0383(0.0042)$ & $0.0561(0.0057)$ & $0.0599(0.0094)$ & $0.0786(0.0058)$ & $0.0642(0.0073)$ \\
\hline South West Thames & 493 & $0.0471(0.0030)$ & $0.0426(0.0037)$ & $0.0422(0.0048)$ & $0.0593(0.0089)$ & $0.0738(0.0049)$ & $0.0791(0.0070)$ \\
\hline South East Thames & 652 & $0.0491(0.0024)$ & $0.0376(0.0026)$ & $0.0347(0.0036)$ & $0.0388(0.0063)$ & $0.0630(0.0031)$ & $0.0600(0.0044)$ \\
\hline North East Thames & 576 & $0.0458(0.0018)$ & $0.0367(0.0023)$ & $0.0380(0.0033)$ & $0.0487(0.0056)$ & $0.0570(0.0028)$ & $0.0516(0.0043)$ \\
\hline North West Thames & 513 & $0.0526(0.0022)$ & $0.0355(0.0026)$ & $0.0365(0.0037)$ & $0.0417(0.0072)$ & $0.0640(0.0036)$ & $0.0566(0.0052)$ \\
\hline Oxford & 552 & $0.0505(0.0037)$ & $0.0385(0.0041)$ & $0.0496(0.0058)$ & $0.0547(0.0086)$ & $0.0670(0.0054)$ & $0.0620(0.0068)$ \\
\hline East Anglia & 573 & $0.0389(0.0051)$ & $0.0281(0.0058)$ & $0.0362(0.0076)$ & $0.0348(0.0104)$ & $0.0618(0.0074)$ & $0.0452(0.0085)$ \\
\hline Midlands & 831 & $0.0467(0.0017)$ & $0.0439(0.0022)$ & $0.0430(0.0029)$ & $0.0678(0.0050)$ & $0.0706(0.0028)$ & $0.0714(0.0035)$ \\
\hline Trent & 832 & $0.0393(0.0019)$ & $0.0441(0.0024)$ & $0.0351(0.0031)$ & $0.0548(0.0051)$ & $0.0646(0.0031)$ & $0.0710(0.0041)$ \\
\hline Merseyside & 312 & $0.0410(0.0020)$ & $0.0395(0.0023)$ & $0.0395(0.0033)$ & $0.0608(0.0054)$ & $0.0570(0.0028)$ & $0.0691(0.0040)$ \\
\hline North Western & 528 & $0.0484(0.0018)$ & $0.0439(0.0022)$ & $0.0404(0.0027)$ & $0.0667(0.0052)$ & $0.0660(0.0026)$ & $0.0714(0.0037)$ \\
\hline Yorkshire & 536 & $0.0417(0.0021)$ & $0.0420(0.0024)$ & $0.0433(0.0036)$ & $0.0511(0.0055)$ & $0.0616(0.0035)$ & $0.0685(0.0041)$ \\
\hline Northern & 675 & $0.0402(0.0019)$ & $0.0370(0.0025)$ & $0.0359(0.0028)$ & $0.0486(0.0046)$ & $0.0580(0.0029)$ & $0.0605(0.0037)$ \\
\hline 11 England & 8464 & $0.0492(0.0006)$ & $0.0439(0.0007)$ & $0.0473(0.0010)$ & $0.0649(0.0017)$ & $0.0712(0.0010)$ & $0.0726(0.0013)$ \\
\hline
\end{tabular}


1 Department of Health. The health of the nation: a strategy for health in England. London: HMSO, 1992

2 Marmot MG, McDowall M. Mortality decline and widening social inequalities. Lancet 1986;ii:274-6.

3 Marmot MG, Shipley MJ, Rose G. Inequalities in death --specific explanations of a general pattern? Lancet 1984;i:1003-6.

4 Marmot MG, Davey Smith G, Stansfeld S, Patel C, North F, Head J, it al. Health inequalities among British civil servants: the Whitehall II study. Lancet 1991;337:1387-93.

5 Goldblatt P. Longitudinal study: mortality and social organisation. London HMSO, 1990. (Series LS, No 6.)

6 Britton M, Fox A, Goldblatt P, Jones DR, Rosato M. The influence of socioeconomic and environmental factors on geographic variation in mortality. In: Britton M, ed. Morality and geography. A rerices in the mid-1980s, England and Wales. London: HMSO, 1990:58-78.

7 Carstairs V, Morris R. Deprivation and health in Scotland. Aberdeen: Aberdeen University Press, 1991.

8 Townsend P, Phillimore P, Beattie A. Health and deprivatim. Inequality and the north. London: Croom Helm, 1988

9 Jarman B. Identification of underprivileged areas. BMF 1983;286:1705-9.

9a Universities of Durham, Edinburgh, Salford. Small area statistics package SASPAC user manual. Vols I and III. Manchester: University of Manchester Computer Centre, 1989

10 Johnson K, Callum C, Killoran A. Appendix 1. In: Johnson K, Callum C, Killoran A, eds. The smoking epidemic. London: Health Education Authority, 1991.

11 Pocock SJ, Cook DG, Shaper AG. Analysing geographic variation in cardiovascular mortality: methods and results. Fournal of the Royal Statistical Society 1982;145:313-41.

12 Pocock SJ, Cook DG, Beresford SAA. Regression of area mortality rates on explanatory variables: what weighting is appropriate? Applied Statistics 1981;30:286-95.

13 Carstairs V, Morris R. Deprivation: explaining differences in mortality between Scotland and England and Wales. BMF 1989;299:886-9.

14 Black D. Inequalities in Health. Report of a research working group. London: Department of Health and Social Security, 1980.

15 Davey Smith G, Bartley M, Blane D. The Black report on socioeconomic inequalitics in health 10 years on. BMF 1990;301:373-7.

16 Mackenbach JP, Bouvier-Colle MH, Jougla E. "Avoidable" mortality and health services: a review of aggregate data studies. $\mathcal{f}$ Epidemiol Community Health 1990;44:106-11.

17 Johnson Z, Jennings S, Fogarty J, Johnson H, Lyons R, Doorley P, et al.
Behavioural risk-factors among young adults in small areas with highmortality versus those in low-mortality areas. Int $f$ Epidemiol 1991;20: 989-96.

18 Haan M, Kaplan GA, Camacho T. Poverty and health. Prospective evidence from the Alameda County study. Am $\mathcal{f}$ Epidemiol 1987;125:989-98

19 Smith SJ. Health status and the housing system. Soc Sci Med 1990;31:753-62.

20 Ross A, Collins M, Sanders C. Upper respiratory tract infection in children, domestic temperatures, and humidity. I Epidemiol Community Health 1990;44:142-6.

21 Pocock SJ, Shaper AG, Cook DG, Packham RF, Lacey RF, Powell P, et al. British regional heart study: geographic variations in cardiovascular mortality, and the role of water quality. BMF 1980;280:1243-9.

22 Elliott P, Hills M, Beresford J, Kleinschmidt I, Jolley D, Pattenden S, et at. Incidence of cancers of the larynx and lung near incinerators of waste solvents and oils in Great Britain Lancet 1992:339:854-7.

23 Graham H. Women's smoking and family health. Soc Sci Med 1987;25:47-56.

24 Smoking. In: General Household Survey 1982: an interdeparmental survey sponsored by the Central Statistical Office. London: HMSO, 1984:189-202.

25 Phillimore PR, Morris D. Discrepant legacies: premature mortality in two industrial towns. Soc Sci Med 1991;33:139-52.

26 Payne JN, Coy J, Milner PC, Patterson S. Are deprivation indicators a proxy for morbidity? A comparison of the prevalence of arthritis, depression, dyspepsia, obseity and respiratory symptoms with unemployment rates and jarman scores. I Public Health Med 1993;15:161-70.

27 Blane D, Davey Smith G, Bartley M. Social class differences in years of potential life lost: size, trends, and principal causes. BMF 1990;301:429-32.

28 Robine JM, Ritchie K. Healthy life expectancy: evaluation of global indicato of change in population health. $B M 71991 ; 302: 457-60$.

29 Mohan J, Killoran A, Johnson K, McKenzie J. Reducing coronary hear disease in England: targets and implications. Health Education foumal 1990;49:176-80.

30 Barker DJP, Osmond C. Infant mortality, childhood nutrition, and ischaemic heart disease in England and Wales. Lancet 1986;: 1077-81.

31 Ben-Shlomo Y, Davey Smith G. Deprivation in infancy or in adult life: which is more important for mortality risk? Lancet 1991; 337:530-5.

32 Egolf B, Lasker J, Wolf S, Potvin L. The Roseto effect: a 50-year comparison of mortality rates. Am f Public Health 1992;82:1089-92.

33 Ashton J. Healthy cities. Milton Keynes: Open University Press, 1992

$34 \mathrm{Mr}$ Major's Dream: is social mobility enough? [Editorial.] Lancet 1990;336: $1547-8$

(Accepted 17 August 1993)
Section of Preventive

Cardiology, Department of

Medicine, Ostra Hospital,

University of Gothenburg,

Sweden

Annika Rosengren, senior

registrar

Lars Wilhelmsen, head of

department

National Institute for

Psychosocial Factors and

Health, Karolinska

Institute, Stockholm,

Sweden

Kristina Orth-Gomér,

professor

Nordic School of Public

Health, Gothenburg,

Sweden

Hans Wedel, professor

Correspondence to:

Dr A Rosengren,

Department of Medicine,

Östra Hospital, S-416 85

Gothenburg, Sweden.

BMf 1993;3071102-5

\title{
Stressful life events, social support, and mortality in men born in 1933
}

\author{
Annika Rosengren, Kristina Orth-Gomér, Hans Wedel, Lars Wilhelmsen
}

\section{Abstract}

Objective-To examine relations between stressful life events and mortality in middle aged men.

Design-Prospective population study. Data on stressful life events, social network, occupation, and other psychosocial factors derived from self administered questionnaires. Mortality data obtained from official registers.

Setting-City of Gothenburg, Sweden.

Subjects-752 men from a random population sample of 1016 men aged 50 .

Main outcome measure-Mortality from all causes during seven years' follow up.

Results-Life events which had occurred in the year before the baseline examination were significantly associated with mortality from all causes during seven years' follow up. Of the men who had experienced three or more events during the past year $10.9 \%$ had died compared with $3.3 \%$ among those with no life events (odds ratio $3.6 ; 95 \%$ confidence interval 1.5 to $8 \cdot 5$ ). The association between recent life events and mortality remained true after smoking, self perceived health, occupational class, and indices of social support were controlled for. Many of the deaths were alcohol related, but the number of deaths was too small to allow for analyses of specific causes of death. The association between life events and mortality was evident only in men with low emotional support.

Conclusion-Stressful life events are associated with high mortality in middle aged men. Men with adequate emotional support seem to be protected.

\section{Introduction}

Psychosocial factors influence mortality. ${ }^{1-8}$ Poor social network, ${ }^{1-4}$ low socioeconomic status, ${ }^{56}$ low social activity, ${ }^{7}$ and bereavement ${ }^{8}$ have all been associated with increased death rates in prospective studies. The concept of emotional stress enters either implicitly or explicitly into most of this research. When examined in epidemiological and clinical investigations life stress may be defined as the numerical accumulation of major life events. ${ }^{9}$ Stress may result either from stressful events in themselves or the person's perception of them. Social support has been suggested to moderate the impact of stress through a buffering effect. ${ }^{1011}$

Life events as a measurement of external life stress was a predominant feature in the research on the influence of stress one or two decades ago. ${ }^{12}$ Early retrospective studies showed adverse life events to be related to various forms of ill health, ${ }^{13-16}$ but prospective studies have yielded conflicting results. ${ }^{17-25}$ Most studies have been conducted in selected populations, and not many have used mortality from all causes as an end point. In recent years interest has shifted towards other psychosocial factors as sources of stress.

To assess the impact of life events on mortality we have investigated data from a cardiovascular survey in middle aged men. In addition to conventional cardiovascular risk factors, the study protocol included questions on several psychosocial factors. Our main hypothesis was that life events predict mortality. In a secondary analysis we investigated whether the potential effect of life events on mortality varied according to level of social support.

\section{Subjects and methods} STUDY POPULATION

In 1983 a random sample was drawn of half of all men in Gothenburg who were born in $1933 .{ }^{26}$ The 1016 men in the sample, all of whom were 50 years old, were invited to a health examination; 776 men $(76 \%)$ responded. 